\title{
Monitoramento e desenvolvimento de indicadores para Políticas de Prevenção de Resíduo Sólido - Estudo de caso: FEC/Unicamp
}

\section{Tayna Zanete Garcia*, Ana Paula Bortoleto}

\section{Resumo}

Este estudo teve como objetivo identificar indicadores para monitorar as atividades de prevenção a serem promovidas pelo plano de gerenciamento de resíduo sólido (RS) da FEC/UNICAMP, visando quantificar a redução na geração de RS e permitir a avaliação do programa para a elaboração de ações de manutenção futuras. A caracterização do RS gerado foi conduzida juntamente com um diagnóstico atual do sistema implantado. Quando comparada com a caracterização anterior de 2015 , percebeu-se uma redução de $10 \%$ no peso total do RS e um aumento de $80 \%$ de plástico descartado. Dessa forma ${ }_{2}$ é possível afirmar a necessidade de minimizar o uso de embalagens descartáveis e de papel branco, além de implementar um sistema de separação eficiente do RS. No caso do monitoramento do sistema de prevenção, selecionou-se os seguintes indicadores: registros fotográficos das lixeiras, número e volume de sacos plásticos recolhidos, composição e peso do RS produzido e número de copos plásticos e garrafas descartados.

\section{Palavras-chave:}

indicadores de monitoramento, gerenciamento de resíduo sólido, prevenção de resíduo sólido.

\section{Introdução}

A prática de Prevenção de Resíduo Sólido é uma estratégia para alcançar a sustentabilidade urbana. No entanto, diversos países europeus, que adotaram medidas de prevenção, apresentaram aumento na quantidade de RS gerado (EEA, 2002). Essa ineficiência pode ser explicada por problemas de monitoramento, sendo necessário identificar indicadores para monitorar essas atividades.

Em 2015, a FEC/Unicamp, através do seu programa FECEnxuta, estabeleceu novas diretrizes para o gerenciamento do RS. Entre elas, destaca-se o programa de prevenção que visa minimizar os impactos ambientais decorrentes da geração RS, que será implantado no segundo semestre de 2018. Neste contexto, este estudo visa contribuir no sucesso da implementação deste programa, através da concepção de indicadores e ferramentas de monitoramento.

\section{Resultados e Discussão}

Em maio de 2018, foi conduzida a caracterização do RS gerado na FEC. Durante sete dias coletou-se o RS gerado em todos os locais do prédio de sala de aulas e administração, excluindo-se banheiros e a cantina. Em seguida, realizou-se a triagem do $\mathrm{RS}$ em cinco categorias: papel, plástico, orgânico, metal e misto e pesou-se cada categoria, obtendo a composição do RS gerado. Posteriormente, os resultados foram comparados com a última caracterização, realizada em 2015, como apresentado na Tabela 1.

Conhecendo a atual composição do resíduo da FEC foi possível determinar quais ações do programa de prevenção provocarão maior impacto. Definiu-se como prioridades a realização de uma campanha para estimular a minimização do resíduo, como papel branco e embalagens plástica e, a instalação de lixeiras padronizadas para separação do RS nas seguintes categorias: garrafas plásticas e latas, papel branco, orgânico e rejeitos.

Tabela 1.Comparação da composição do RS da FEC

\begin{tabular}{|c|c|c|c|c|c|}
\hline \multirow{2}{*}{ Material } & \multicolumn{2}{|c|}{ Caracterizção - 2015 } & \multicolumn{2}{c|}{ Caracterizaçäo - 2018 } & Variação do \\
\cline { 2 - 5 } & Peso $\mathbf{( k g )}$ & $\mathbf{( \% )}$ & Peso $\mathbf{( k g )}$ & $\mathbf{( \% )}$ & Peso $\mathbf{\%})$ \\
\hline Metal & 0,116 & 0,83 & 0,1 & 1,03 & $-13,79$ \\
\hline Misto & 0,270 & 1,94 & 0,4 & 3,08 & 48,15 \\
\hline Plástico & 1,220 & 8,78 & 2,2 & 17,45 & 80,33 \\
\hline Orgânico & 4,127 & 29,69 & 3,1 & 24,63 & $-24,88$ \\
\hline Papel & 8,167 & 58,76 & 6,7 & 53,82 & $-17,96$ \\
\hline Total & 13,900 & 100,00 & 12,5 & 100,00 & $-10,07$ \\
\hline
\end{tabular}

Para monitorar este programa desenvolveu-se dois tipos de indicadores:

(i) os visuais, que consistem em registros fotográficos do interior das lixeiras, retiradas anualmente em um dia aleatório, visando verificar se a separação é realizada de maneira adequada pela comunidade;

(ii) os quantitativos, que consistem no número e volume diário de sacos plásticos recolhidos destinados à reciclagem, contabilizados pela equipe de limpeza; na composição e peso do RS produzido e no número de copos plásticos e garrafas descartados, ambos obtidos através da caracterização do RS realizada semestralmente.

\section{Conclusões}

Para monitorar as ações do programa de prevenção de RS na FEC e direcionar as possíveis adequações, foram desenvolvidos indicadores visuais que avaliam a participação da comunidade e quantitativos, que contabilizam a minimização do RS e possibilitam estimar o impacto ambiental evitado.

\section{Agradecimentos}

Agradeço à FEC, à Prof ${ }^{a}$. Dra. Ana Paula, às equipes do setor de facilidades e de limpeza e ao PIBIC/CNPq pelo apoio ao projeto.

EEA - European Environment Agency. (2002). Case studies on waste minimisation practices in Europe, Topic report 2/2002, Copenhagen. 